Editorial

\title{
Access to medicines - overcoming the barriers
}

\author{
Hazel Bradley ${ }^{7}$ and Richard Laing ${ }^{2}$
}

The Global Burden of Disease, especially in the Middle East, is rapidly shifting from acute to chronic noncommunicable diseases (NCDs). This has been recognized by the holding of the UN General Assembly High-level Meeting on the prevention and control of NCDs in September 2011. Following the political declaration passed by the Assembly, the World Health Organization (WHO) was tasked with the responsibility to define indicators and targets. One of the key targets is an $80 \%$ availability of the affordable basic technologies and essential medicines, including generics, required to treat major NCDs, in both public and private facilities. Access encompasses more than just availability; it includes geographical access, often affected by travel costs and time, cultural access often involving gender and minority issues, and financial access involving prices and ability to pay.

Existing health systems will have to change to accommodate new demands for NCD care, particularly in the public sector. Most existing systems and facilities have an historical acute focus on children and frequent infections or emergencies. Patients with NCDs are usually well when they attend health facilities and need monitoring, reliable medical supplies, adherence support with registers, and follow up of nonattenders. Learning from the success of HIV/AIDS and TB treatment programmes we know that such services can be provided to poor people in poor countries; however, very few systems have changed to provide such long-term care for patients with cardiovascular disease or diabetes or depression!

The difference in availability of NCD medicines compared to acute medicines was highlighted by Cameron et al. in 2011 (1). They showed that in the public sector NCD medicines were $17.5 \%$ less available than acute medicines while in the private sector the difference was $11.5 \%$. In low-income countries the difference in the public sector was more than $33 \%$. These differences mean that patients with these NCDs have to source their medicines from the private sector at prices five to eight times higher than international reference prices or national tender prices.

Nearly all of the essential NCD medicines are off-patent and should be available as generic medicines but, as was reported in the 2010 World Health Report and later by Cameron and others, countries could save between 60 and $70 \%$ of their total pharmaceutical expenditure by shifting from high cost originator or branded generic medicines to International Nonproprietary Name (INN) generic medicines $(2,3)$.

The changing disease burden to chronic NCDs places new demands on health systems, in a Region in which $40 \%$ of countries were found to have weak health systems (4). This includes the re-orientation and strengthening of health systems to new models of care which require health workers to be trained in providing long-term care to patients with chronic conditions and the optimal use of scarce human resources. This may involve task-shifting and the introduction of new mid-level cadres to ensure ease of access for patients to obtain medicines regularly (5). In addition, people with chronic NCDs will need to be supported to manage their medicines for their conditions through education, self-management and care (6).

Although HIV/AIDS treatment programmes have demonstrated the value of treatment registers to monitor retention in care, the situation in South Africa has shown that as programmes go to scale there are challenges in maintaining high levels of adherence to treatment required by HIV/AIDS (7). The practicalities of introducing similar systems for chronic NCDs will likely be extremely challenging.

There are many examples where achievements have been made. In 2011, Health Action International reviewed the procurement performance of the UNRWA supply of medicines to their camps in the Syrian Arab Republic, Lebanon, Jordan, West Bank and Gaza. Despite the relatively small size of their orders and the challenges of the political turmoil in their areas of work, the review showed a very creditable performance. Compared to international reference prices maintained by Management Sciences for Health, Jordan's Joint Procurement Department, Gulf Cooperation Council Prices and the International Dispensary Association, UNRWA prices overall for a basket of 80 medicines were equal or cheaper. For a few medicines UNRWA paid more than one or more comparators but for most they did better. This demonstrates 
that efficient procurement, even with relatively small volumes, can occur with favourable prices $(4,8)$.

An innovative response to delivering regular medication to patients with chronic diseases in the Western Cape Province in South Africa is the Chronic Dispensing Unit (CDU), a public-private partnership between the Western Cape government and a private provider established in 2005 (9). Each month the CDU distributes approximately 240000 patient-ready packages containing one or two months' supply of medication to over 200 primary health care clinics or community sites across the province. This government initiative has reduced waiting times for patients collecting monthly supplies of chronic medicines in clinics and facilitated several community-based distribution initiatives involving community health workers. Availability of medicines is over $98 \%$ !
In conclusion, the global shift from acute to chronic NCDs requires a change in health systems from oneoff care episodes to long-term care. Access to medicines now implies life-long availability, affordability and rational use with the patients, who quickly become expert in all aspects of their condition, being integral participants. This requires a change in the mindset of health programme managers.

\section{References}

1. Cameron A, Roubos I, Ewen M, Mantel-Teeuwisse AK, Leufkens HG, Laing RO. Differences in the availability of medicines for chronic and acute conditions in the public and private sectors of developing countries. Bull World Health Organ. 2011 Jun 1;89(6):412-21. PMID:21673857

2. Cameron A, Laing R. Cost savings of switching private sector consumption from originator brand medicines to generic equivalents. World Health Report (2010) Background Paper, No 35. Geneva, World Health Organization, 2010 (http:// www.who.int/entity/healthsystems/topics/financing/healt hreport/35MedicineCostSavings.pdf, accessed 15 April 2015)

3. Cameron A, Mantel-Teeuwisse AK, Leufkens HG, Laing RO. Switching from originator brand medicines to generic equivalents in selected developing countries: how much could be saved? Value Health. 2012 Jul-Aug;15(5):664-73. PMID:22867775

4. Civil registration and vital statistics systems in the Region [online database]. Cairo; World Health Organization Regional Office for the Eastern Mediterranean (http://www.emro.who. int/entity/statistics/statistics.html, accessed 15 April 2015).
5. Joshi R, Alim M, Kengne AP, Jan S, Maulik PK, Peiris D, et al. Task shifting for non-communicable disease management in low and middle income countries-a systematic review. PLoS One. 2014;9(8):e103754. PMID:25121789

6. van Olmen J, Ku GM, Bermejo R, Kegels G, Hermann K, Van Damme W. The growing caseload of chronic life-long conditions calls for a move towards full self-management in low-income countries. Global Health. 2011;7(38):38. PMID:21985187

7. Bekker LG, Venter F, Cohen K, Goemare E, Van Cutsem G, Boulle A, et al. Provision of antiretroviral therapy in South Africa: the nuts and bolts. Antivir Ther. 2014;19 Suppl 3:105-16. PMID:25310359

8. Medicine procurement prices and processes. Amman, United Nations Relief and Works Agency for Palestine Refugees in the Near East (UNRWA), 2012 (http://apps.who.int/medicinedocs/documents/s19903en/s19903en.pdf, accessed 15 April 2015).

9. du Toit J, Dames S, Boshoff R. Central Dispensing - an affordable solution. S Afr Pharm J. 2008; (Nov/Dec);75(10):18-20. 